\title{
Poly(3-hexylthiophene)/ZnO hybrid pn junctions for microelectronics applications
}

Katsia, E.; Huby, N.; Tallarida, G.; Kutrzeba-Kotowska, B.; Perego, M.; Ferrari, S.; Krebs, Frederik C; Guziewicz, E.; Godlewski, M.; Osinniy, V.

Total number of authors:

11

Published in:

Applied Physics Letters

Link to article, DOI:

$10.1063 / 1.3114442$

Publication date:

2009

Document Version

Publisher's PDF, also known as Version of record

Link back to DTU Orbit

Citation (APA):

Katsia, E., Huby, N., Tallarida, G., Kutrzeba-Kotowska, B., Perego, M., Ferrari, S., Krebs, F. C., Guziewicz, E., Godlewski, M., Osinniy, V., \& Luka, G. (2009). Poly(3-hexylthiophene)/ZnO hybrid pn junctions for

microelectronics applications. Applied Physics Letters, 94(14), 143501. https://doi.org/10.1063/1.3114442

\section{General rights}

Copyright and moral rights for the publications made accessible in the public portal are retained by the authors and/or other copyright owners and it is a condition of accessing publications that users recognise and abide by the legal requirements associated with these rights.

- Users may download and print one copy of any publication from the public portal for the purpose of private study or research.

- You may not further distribute the material or use it for any profit-making activity or commercial gain

- You may freely distribute the URL identifying the publication in the public portal 


\title{
Poly(3-hexylthiophene)/ZnO hybrid pn junctions for microelectronics applications
}

\author{
E. Katsia, ${ }^{1}$ N. Huby, ${ }^{1}$ G. Tallarida, ${ }^{1, a)}$ B. Kutrzeba-Kotowska, ${ }^{1}$ M. Perego, ${ }^{1}$ S. Ferrari, ${ }^{1}$ \\ F. C. Krebs, ${ }^{2}$ E. Guziewicz, ${ }^{3}$ M. Godlewski, ${ }^{3}$ V. Osinniy, ${ }^{3}$ and G. Luka ${ }^{3}$ \\ ${ }^{1}$ Laboratorio Nazionale MDM, CNR-INFM, Via Olivetti 2, 20041 Agrate Brianza, Milan, Italy \\ ${ }^{2}$ Ris $\phi$ National Laboratory for Sustainable Energy, Technical University of Denmark, Frederiksborgvej 399, \\ DK-4000 Roskilde, Denmark \\ ${ }^{3}$ Institute of Physics, Polish Academy of Sciences, al. Lotnikòw 32/46, 02-668 Warsaw, Poland
}

(Received 4 October 2008; accepted 14 March 2009; published online 6 April 2009)

\begin{abstract}
Hybrid poly(3-hexylthiophene)/ZnO devices are investigated as rectifying heterojunctions for microelectronics applications. A low-temperature atomic layer deposition of $\mathrm{ZnO}$ on top of poly(3-hexylthiophene) allows the fabrication of diodes featuring a rectification ratio of nearly $10^{5}$ at $\pm 4 \mathrm{~V}$ and a current density of $10^{4} \mathrm{~A} / \mathrm{cm}^{2}$. Electrical characteristics are discussed taking into account the chemical structure of the stack and the energy band diagram. () 2009 American Institute of Physics. [DOI: 10.1063/1.3114442]
\end{abstract}

Hybrid organic/inorganic devices are gaining an increasing scientific and technological interest for the possibility of combining the versatility of the chemical structure of organic materials with the established properties of inorganic compounds. Such devices have been investigated so far mainly for their potential application in optoelectronics and photovoltaics, such as light emitting diodes and photodetectors. ${ }^{1-3}$ Hybrid devices may play a significant role also in the field of nonvolatile memory (NVM) technology, where the request for high density and low cost devices motivates the research for innovative device architectures.

In this work we propose a hybrid rectifying junction based on poly(3-hexylthiophene) (P3HT) and $\mathrm{ZnO}$ as selector for cross-point NVM devices, where the memory element and its selector are stacked one on top of the other between two metal wires and are fabricated at the back end of the line (BEOL) level. ${ }^{4}$ The selector, i.e., a suitable rectifying element for avoiding misreading and misprogramming of the unselected memory cells, ${ }^{5}$ has to sustain a sufficient high current density for high speed operation and to provide a high rectification ratio. ${ }^{4}$ The low thermal budget imposed by BEOL processes rules out silicon based devices and drives the search for nonconventional materials. Organic semiconductor based devices have the advantage of the low thermal budget required for processing and the low fabrication cost, but are generally characterized by low carrier mobility that limits the forward current. Combination with inorganic semiconductors might overcome this drawback.

Zinc oxide is widely studied for optoelectronics applications. ${ }^{6} \mathrm{ZnO}$ is normally $n$-type doped and despite the extensive research work on the subject, ${ }^{6-8}$ stable $p$-type $\mathrm{ZnO}$ is difficult to be obtained; thus hindering the fabrication of $\mathrm{ZnO} p-n$ homojunctions. Also for this reason, several hybrid $p$-type organic $/ n-\mathrm{ZnO}$ junctions have been proposed in recent years. Rectifying $p-n$ pentacene/ $\mathrm{ZnO}$ diodes were recently reported with a high current density and stability in the atmosphere for potential application in high frequency RF-ID (radiofrequency identification) tags. ${ }^{9}$ Mridha and Basak $^{10}$ showed that a structure based on ZnO/PANI reveals

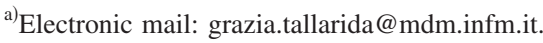

a rectifying behavior suitable for fabricating UV photodetectors. Atomic layer deposition (ALD) of $\mathrm{ZnO}$ provides the advantages of (i) producing uniform polycrystalline layers under low-temperature conditions without involving high energy processes, with optimum electrical properties ${ }^{11}$ and (ii) allowing atomic layer control of thickness and composition, due to the surface limited reaction of the precursors. ${ }^{12}$ The low growth temperature allows growing the inorganic material on top of the organic. Therefore, the inorganic part acts as a capping layer protecting the underneath more sensitive organic compound from damaging during device fabrication and degradation due to the environmental conditions.

P3HT was chosen as the $p$-type organic compound since it is an effective hole transport material in its regioregular (RR) form with relatively high charge carrier mobility. ${ }^{13,14}$ Several publications are also reported incorporating this material in hybrid structures with different inorganic compounds showing promising electrical characteristics. ${ }^{1,15}$

The growth of $\mathrm{ZnO}$ on P3HT was analyzed by scanning electron microscope (SEM) and time of flight-secondary ion mass spectroscopy (ToF-SIMS) on flat samples, having nominal thickness of 60 and $90 \mathrm{~nm}$, respectively.

$\mathrm{Au} / \mathrm{P} 3 \mathrm{HT} / \mathrm{ZnO} / \mathrm{Al}$ diodes were integrated into crossbar structures using the integration route we recently proposed. ${ }^{16}$ The junctions were built on a Si $n^{+}$wafer coated with 100 $\mathrm{nm}$ thermal silicon dioxide. Bottom electrodes were fabricated by e-beam assisted evaporation and patterning of a 40 $\mathrm{nm}$ thick gold film; a thin Ti layer was first deposited for promoting adhesion. $\mathrm{SiO}_{2}(50 \mathrm{~nm}$ thick) was used as dielectric matrix where square holes are patterned to define diode areas. RR-P3HT (97\%-98\%) was spin coated from a toluene solution, producing a layer of approximately $30 \mathrm{~nm}$ inside the patterned structures, as measured by a stylus profilometer. $\mathrm{ZnO}$ was grown on top of the already patterned P3HT in a commercial ALD reactor (Cambridge Nanotech Savannah 100 , USA) at $100{ }^{\circ} \mathrm{C}$ from diethyl zinc $\left[\mathrm{Zn}\left(\mathrm{CH}_{3} \mathrm{CH}_{2}\right)_{2}\right]$ and de-ionized water precursors, with an expected thickness of $90 \mathrm{~nm}$. Details of the specific conditions and film properties can be found elsewhere. ${ }^{17}$ Finally, $\mathrm{Al}$ top electrode (100 nm thick) was thermally evaporated and patterned by lift-off. An optical microscope image of the $\mathrm{Au} / \mathrm{P} 3 \mathrm{HT} / \mathrm{ZnO} / \mathrm{Al}$ crossbar 


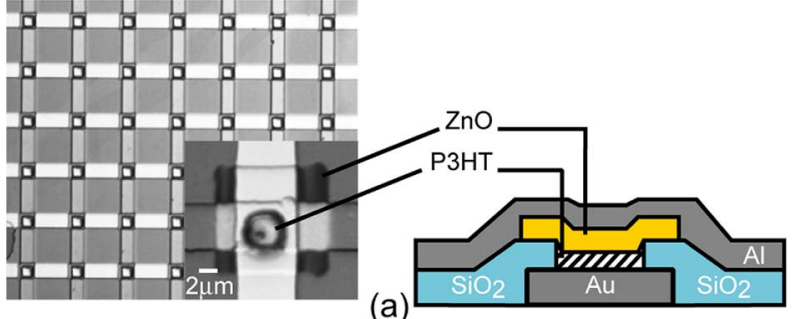

FIG. 1. (Color online) (a) Optical microscope image of an $\mathrm{Al} / \mathrm{ZnO} /$ $\mathrm{P} 3 \mathrm{HT} / \mathrm{Au}$ crossbar array; in the inset a $4 \times 4 \mu \mathrm{m}^{2}$ cross-point diode is shown. (b) Schematic of the diode cross section.

array and a schematic of the diode cross section are shown in Fig. 1. $J-V$ characteristics reported in this work were measured on diodes with a cross-point area of $4 \times 4 \mu \mathrm{m}^{2}$.

Figure 2 (top left) depicts the SEM image of the P3HT/ $\mathrm{ZnO}$ cross section. The $\mathrm{ZnO}$ layer is uniform and grows conformal to P3HT. This is also confirmed by atomic force microscopy (AFM) measurements of the surface morphology, which results homogeneous and whose roughness does not increase after $\mathrm{ZnO}$ film growth. For comparison, the SEM image of a $\mathrm{ZnO}$ layer grown at similar conditions on a silver film is also reported (Fig. 2, bottom left). The image of $\mathrm{ZnO}$ grown on the metal layer shows a well-defined polycrystalline material, with crystals growing perpendicular to the surface. On the other hand, the P3HT/ZnO interface is less sharp, indicating a possible intermixing between the two compounds. This is also suggested by the fact that the thickness of $\mathrm{ZnO}$, estimated by SEM images by measuring the distinct $\mathrm{ZnO}$ layer, appears lower than the expected. To address this point, a chemical characterization of the stack was performed by ToF-SIMS analysis.

The ToF-SIMS profile of the $\mathrm{ZnO} / \mathrm{P} 3 \mathrm{HT}$ stack is reported in Fig. 2 (right). The $\mathrm{ZnO}_{2}{ }^{-}$signal refers to the $\mathrm{ZnO}$ distribution, whereas $\mathrm{S}^{-}$and $\mathrm{C}_{4}{ }^{-}$are indicative of the presence of P3HT. The Au, S, and C signals denote clearly the interface between the P3HT layer and the Au film. An Au tail extending into the P3HT can be observed, which could be attributed to occasional pinholes that are present in the organic layer; however, their density (estimated from AFM measurements $\leq 10^{6} \mathrm{~cm}^{-2}$ ) is low enough not to affect most of the patterned P3HT square diodes. The $\mathrm{ZnO}$ signal decreases gradually inside the $\mathrm{P} 3 \mathrm{HT}$ region, indicating that

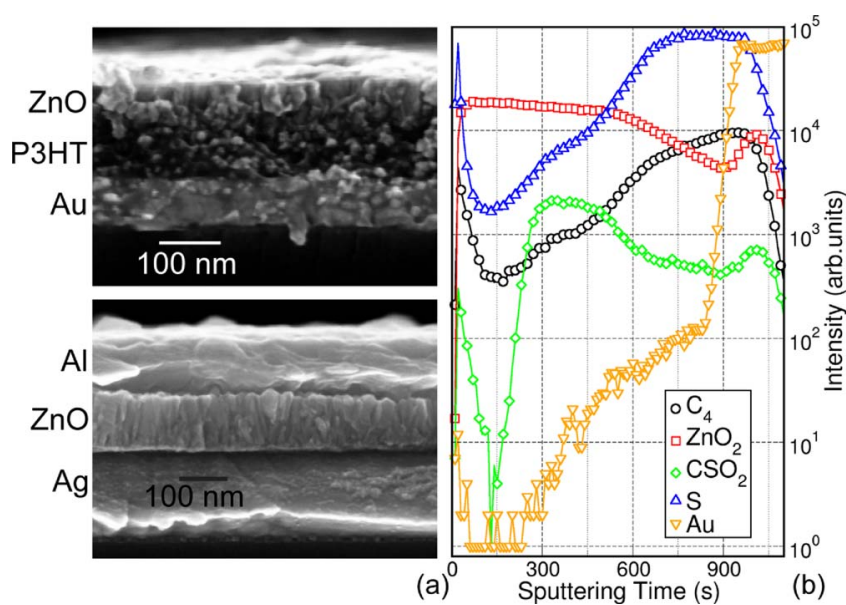

FIG. 2. (Color online) (a) Cross-section SEM images of an Au/P3HT/ZnO structure (top image) and an $\mathrm{Ag} / \mathrm{ZnO} / \mathrm{Al}$ structure (bottom image). (b) ToFSIMS profile of the $\mathrm{ZnO} / \mathrm{P} 3 \mathrm{HT}$ stack on Au substrate.

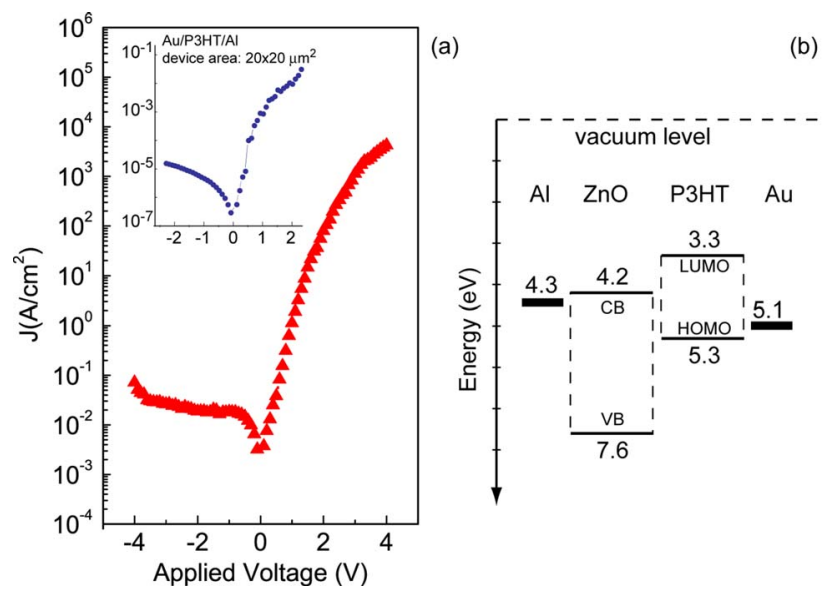

FIG. 3. (Color online) (a) Typical current-voltage characteristics of a $4 \times 4 \mu \mathrm{m}^{2} \mathrm{Al} / \mathrm{ZnO} / \mathrm{P} 3 \mathrm{HT} / \mathrm{Au}$ device. In the inset the typical $J-V$ characteristics of an Au/P3HT/Al Schottky junction (Ref. 17) is presented for comparison. (b) Energy band diagram in nonequilibrium conditions of the $\mathrm{Al} /$ $\mathrm{ZnO} / \mathrm{P} 3 \mathrm{HT} / \mathrm{Au}$ stack.

some diffusion into the organic layer is taking place. This indication is further supported by the behavior of the $\mathrm{CSO}_{2}^{-}$ signal. This signal is lower inside $\mathrm{P} 3 \mathrm{HT}$ and increases in the region around the $\mathrm{P} 3 \mathrm{HT} / \mathrm{ZnO}$ interface; then stabilizes and finally shows a sharp decrease at the surface. These results indicate that the stack consists of three different regions: a superficial layer (up to $300 \mathrm{~s}$ sputtering time) where $\mathrm{C}$ and $\mathrm{S}$ contaminations are limited and the film is virtually $\mathrm{ZnO}$; an interfacial region (between 300 and $600 \mathrm{~s}$ sputtering time), where the two compounds are intermixed; and a region close to the gold layer mainly comprising P3HT. It must be underlined that the broadening of the $\mathrm{ZnO} / \mathrm{P} 3 \mathrm{HT}$ interface is not an artifact induced by the ion bombardment process during the measurements. In fact, we verified that the signal distribution is independent from the sputtering energy. We suggest that the broad interfacial region is generated by the diffusion, during the first stages of growth, of the $\mathrm{Zn}$ precursor and water inside P3HT, facilitated by the porosity of the organic film. This diffusion might also lead to the formation of $\mathrm{ZnO}$ clusters inside the organic layer. After a certain number of deposition cycles, the P3HT is completely covered with $\mathrm{ZnO}$; from this stage on, the incoming precursors "see" a uniform $\mathrm{ZnO}$ surface and the growth of polycrystalline $\mathrm{ZnO}$ film is initiated on the surface. This mechanism would also explain the reduced $\mathrm{ZnO}$ layer thickness observed from SEM images compared to the expected one.

Figure 3(a) presents the typical electrical characteristics of a $\mathrm{P} 3 \mathrm{HT} / \mathrm{ZnO}$ junction fabricated into a crossbar configuration with a cross-point area of $4 \times 4 \mu \mathrm{m}^{2}$ and a P3HT thickness of $30 \mathrm{~nm}$. In the inset of the figure, the $J-V$ characteristics of a Au/P3HT/Al Schottky diode with an active area of $20 \times 20 \mu \mathrm{m}^{2}$ is reported for comparison. ${ }^{16}$ The $\mathrm{P} 3 \mathrm{HT} / \mathrm{ZnO}$ junction shows a high rectifying ratio of $10^{5}$ at $\pm 4 \mathrm{~V}$. A remarkable feature is the high current density obtained at $4 \mathrm{~V}$, nearly $10^{4} \mathrm{~A} / \mathrm{cm}^{2}$, which is more than five orders of magnitude higher than in the P3HT device. Moreover, the reverse current is nearly constant up to $-3.5 \mathrm{~V}$ and significantly lower than in $\mathrm{Al} / \mathrm{ZnO} / \mathrm{Ag}$ Schottky diodes of Ref. 18, comprising a similar $\mathrm{ZnO}$ layer.

This result can be explained considering the energy band diagram of the layers depicted in Fig. 3(b). ${ }^{6,19}$ The resulting heterojunction is a staggered one, where the barrier for elec- 
tron diffusion is significantly lower than that for holes, and therefore electrons are expected to be the dominant charge carriers. Indeed, when the junction is forward biased, electrons are effectively injected from $\mathrm{ZnO}$ side, whereas in reverse bias both electrons and holes encounter a significant potential barrier. It has been reported that electron mobility in RR-P3HT is comparable to the hole one, ${ }^{20}$ and that the absence of $n$-type transport in this material is generally related to high injection barriers, rather than to its intrinsic charge transport properties. ${ }^{21}$ Moreover, the P3HT layer is only $30 \mathrm{~nm}$ thick, thus limiting the series resistance of the junction. Finally, one has to consider that, during the growth of $\mathrm{ZnO}$, the P3HT is kept at $100{ }^{\circ} \mathrm{C}$ for more than $3 \mathrm{~h}$; thus inducing a thermal annealing of the polymer layer, which probably improves its electrical characteristics. ${ }^{22}$ Although, this simple picture applies for abrupt junctions, which is not the case here, where most probably a graded junction is forming at the organic/inorganic interface, we believe it gives a consistent qualitative interpretation of the observed results. It is noteworthy mentioning that the $J-V$ curves reported in Fig. 3(a) are necessarily due to the formation of a $p$ - $n$ junction at the $\mathrm{P} 3 \mathrm{HT} / \mathrm{ZnO}$ interface and cannot be attributed to the formation of a $\mathrm{Au} / \mathrm{ZnO} / \mathrm{Al}$ junction. In fact, if this were the case, we would observe a worse rectification ratio and a stronger field dependence of the reverse current, because gold does not form a good Schottky contact with $\mathrm{ZnO}$, unless specific postdeposition treatments are applied. ${ }^{23}$

To conclude, the results reported above for $\mathrm{P} 3 \mathrm{HT} / \mathrm{ZnO}$ junctions are promising for those applications in microelectronics where low-temperature high quality $p$ - $n$ junctions are required, such as crossbar based nonvolatile memory devices.

This work was performed in the framework of the FP6 EU STREP project VERSATILE, Contract No. 026714.

${ }^{1}$ C. H. Chen and I. Shih, J. Mater. Sci.: Mater. Electron. 17, 1047 (2006). ${ }^{2}$ C. R. Kagan, D. B. Mitzi, and C. D. Dimitrakopoulos, Science 286, 945 (1999).
${ }^{3}$ N. Tessler, M. Medvedev, M. Kazes, S. Kan, and U. Banin, Science 295, 1506 (2002).

${ }^{4}$ M.-J. Lee, S. Seo, D.-C. Kim, S.-E. Ahn, D. H. Seo, I.-K. Yoo, I.-G. Baek, D.-S. Kim, I.-S. Byun, S.-H. Kim, I.-R. Hwang, J.-S. Kim, S.-H. Jeon, and B. H. Park, Adv. Mater. (Weinheim, Ger.) 19, 73 (2007).

${ }^{5}$ M.-J. Lee, Y. Park, B.-S. Kang, S.-E. Ahn, C. Lee, K. Kim, W. Xianyu, G. Stefanovich, J.-H. Lee, S.-J. Chung, Y.-H. Kim, C.-S. Lee, J.-B. Park, I.-G. Baek, and I.-K. Yoo, Tech. Dig. - Int. Electron Devices Meet. 2007, 771

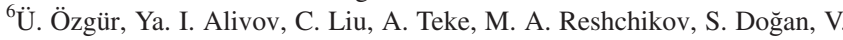
Avrutin, S.-J. Cho, and H. Morkoç, J. Appl. Phys. 98, 041301 (2005).

${ }^{7}$ S. T. Tan, X. W. Sun, Z. G. Yu, P. Wu, G. Q. Lo, and D. L. Kwong, Appl. Phys. Lett. 91, 072101 (2007).

${ }^{8}$ R. Ding, H. Zhu, and Q. Zeng, Vacuum 82, 510 (2008).

${ }^{9}$ B. N. Pal, J. Sun, B. J. Jung, E. Choi, A. G. Andreou, and H. E. Katz, Adv. Mater. (Weinheim, Ger.) 20, 1023 (2008).

${ }^{10}$ S. Mridha and D. Basak, Appl. Phys. Lett. 92, 142111 (2008).

${ }^{11}$ N. Huby, S. Ferrari, E. Guziewicz, M. Godlewski, and V. Osinniy, Appl. Phys. Lett. 92, 023502 (2008).

${ }^{12}$ L. Niinistö, J. Päiväsaari, J. Niinistö, M. Putkonen, and M. Nieminen, Phys. Status Solidi A 201, 1443 (2004).

${ }^{13}$ H. Sirringhaus, N. Tessler, and R. H. Friend, Science 280, 1741 (1998).

${ }^{14}$ H. Sirringhaus, P. J. Brown, R. H. Friend, M. M. Nielsen, K. Bechgaard, B. M. W. Langeveld-Voss, A. J. H. Spiering, R. A. J. Janssen, E. W. Meijer, P. Herwig, and D. M. de Leeuw, Nature (London) 401, 685 (1999).

${ }^{15}$ W. U. Huynh, J. J. Ditmtmer, and A. P. Alivisatos, Science 295, 2425 (2002).

${ }^{16}$ E. Katsia, G. Tallarida, B. Kutrzeba-Kotowska, S. Ferrari, E. Bundgaard, R. Søndergaard, and F. C. Krebs, Org. Electron. 9, 1044 (2008).

${ }^{17}$ A. Kowalik, E. Guziewicz, K. Kopalko, S. Yatsunenko, M. Godlewski, and A. Wojcik, Acta Phys. Pol. A 112, 401 (2007).

${ }^{18}$ N. Huby, G. Tallarida, M. Kutrzeba, S. Ferrari, E. Guziewicz, Ł. Wachnicki, and M. Godlewski, Microelectron. Eng. 85, 2442 (2008).

${ }^{19}$ C. H. Lei, A. Das, M. Elliott, J. E. Macdonald, and M. L. Turner, Synth. Met. 145, 217 (2004).

${ }^{20}$ S. A. Choulis, Y. Kim, J. Nelson, D. D. C. Bradley, M. Giles, M. Shkunov, and I. McCulloch, Appl. Phys. Lett. 85, 3890 (2004).

${ }^{21}$ E. J. Meijer, D. M. De Leeuw, S. Setayesh, E. Van Veenendaal, B.-H. Huisman, P. W. M. Blom, J. C. Hummelen, U. Scherf, and T. M. Klapwijk, Nature Mater. 2, 678 (2003).

${ }^{22}$ S. Cho, K. Lee, J. Yuen, G. Wang, D. Moses, A. J. Heeger, M. Surin, and R. Lazzaroni, J. Appl. Phys. 100, 114503 (2006).

${ }^{23}$ Q. L. Gu, C. C. Ling, X. D. Chen, C. K. Cheng, A. M. C. Ng, C. D. Beling, S. Fung, G. Brauer, and H. C. Ong, Appl. Phys. Lett. 90, 122101 (2007) 